\title{
Nondestructive Evaluation Techniques for Enhanced Bridge Inspection
}

\section{Graham Thomas, Steven Benson, Philip Durbin, Nancy Del Grande, Jerry Haskins, Albert Brown and Daniel Schneberk}

This paper was prepared for submittal to the Quantitative Nondestructive Evaluation (QNDE) 193 Conference Brunswick, Maine August 1-6, 1993

October 1993

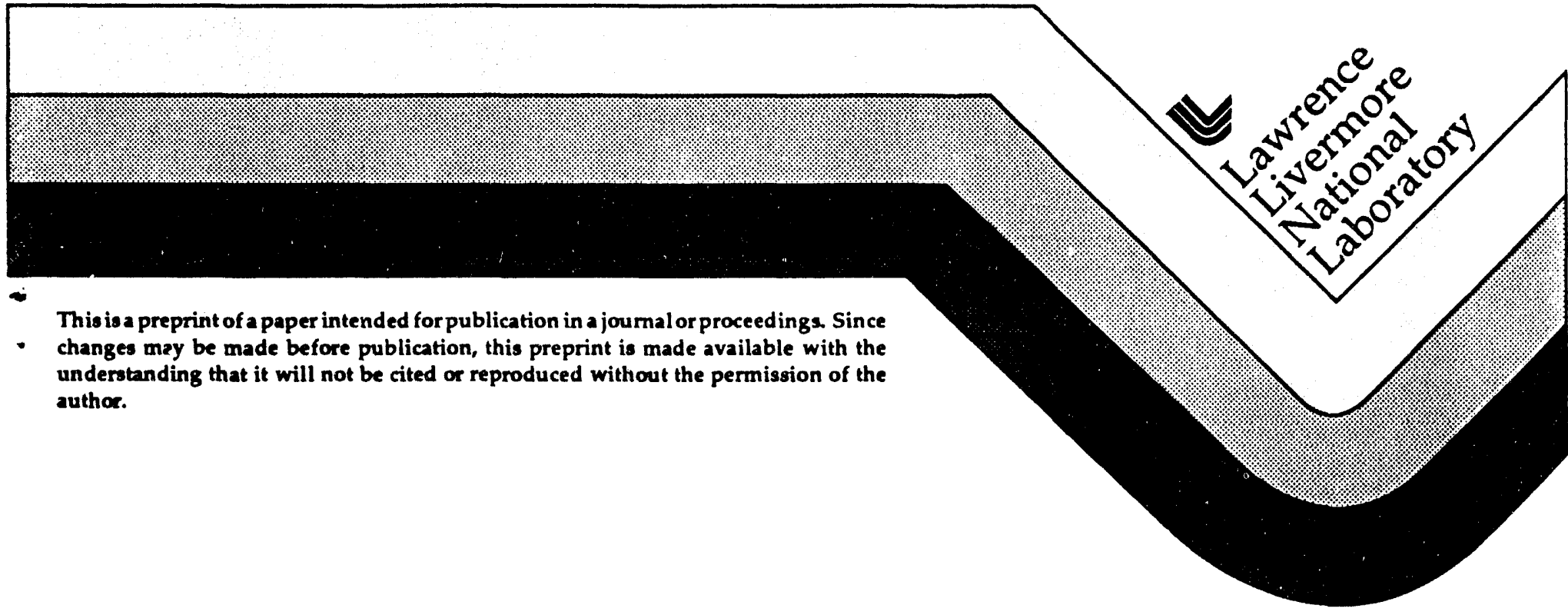




\section{DISCLAIMER}

This document was prepared as an account of work sponsored by an agency of the L'nited States Government. Neither the L'nited States Government nor the Liniversity of California nor any of their employees, makes any warranty, express or implied, or assumes any legal tiability or responsibility for the accuracy, completeness, or usefulness of any information. apparatus, product, or process disclosed, or represents that its use would not infringe privately owned rights. Reference herein to any specific commercial products, process, or service by trade name, trademark, manufacturer. or otherwise, does not necessarily constitute or imply its endorsement, recommendation, or favoring by the $L_{\text {inited }}$ States Government or the Lniversity of California. The views and opinions of authors expressed herein do not necessarily state or reflect those of the L'nited States Government thereof, and shall not be used for advertising or product endorsement purposes. 


\title{
Nondestructive Evaluation Techniques for Enhanced Bridge Inspection
}

\author{
Graham Thomas, Steve Benson, Phil Durbin, Nancy Del Grande, \\ Jerry Haskins, Al Brown, and Dan Schneberk \\ Lawrence Livermore National Laboratory \\ Livermore, California 94550
}

\section{Introduction}

Nondestructive evaluation of bridges is a critical aspect in the U.S. aging infrastructure problem. For example in California there are 26,000 bridges, 3000 are made of steel, and of the steel bridges, 1000 are fracture critical. California Department of Transportation (Caltrans), Federal Highway Administration, and Lawrence Livermore National Laboratory (LLNL) are collaborating to develop and field NDE techniques to improve bridge inspections. We have demonstrated our NDE technologies on several bridge inspection applications. An early collaboration was to ultrasonically evaluate the steel pins in the E-9 pier on the San Francisco Bay Bridge. Following the Lcma-Prieta earthquake in 1989 and the road way collapse at the E-9 pier, a complete nondestructive evaluation was conducted by Caltrans inspectors and several ultrasonic indications were noted. LLNL worked with Caltrans to help indentify the source of these reflections. Another project was to digitally enhance high energy radiographs of bridge components such as cable end caps. We demonstrated our ability to improve the detection of corrosion and fiber breakage inside the end cap. An extension of this technology is limited view computer tomography (CT). We implemented our limited view CT software and produced cross-sectional views of bridge cables from digitized radiographic films. Most recently, we are developing dual band infrared imaging techniques to assess bridge decks for delaminations. We have demonstrated the potential of our NDE technology for enhancing the inspection of the country's aging bridges. 


\section{Projects}

Ultrasonics

Lawrence Livermore National Laboratory and California Department of Transportation have been collaborating to develop and field NDE techniques to improve bridge inspections. One particular effort has been to ultrasonically evaluate the steel pins in the E-9 pier on the San Francisco Bay Bridge. After the Loma-Prieta earthquake in 1989 and the road way collapsed at the E-9 pier, a complete nondestructive evaluation was conducted by Caltrans on that structure. A result of the inspection was ultrasonic indications in two of the large steel pins. These ultrasonic indications were located in the pin where there was a gap between eye bars, see Figure 1 . The indications were detected by a contact, pulse-echo, longitudinal wave ultrasonic technique from the end of the pins. Before expensive corrective actions were implemented, the indications needed to be confirmed as cracks.

The original longitudinal ultrasonic inspection was complemented with other ultrasonic techniques to determine the nature of the reflector in the pin. A specially designed wand with angle beam transducers was fabricated to fit in the central hole in the pin. The angle beam technique insonofied the reflector with 45 degree, shear waves which provided another viewing angle. Since it is difficult to distinguish a crack from other reflectors with a single view longitudinal wave evaluation, adding another view with the shear wave helps characterize the reflector. A crack will interact with the ultrasonic energy differently than other reflectors. A calibration reference pin was fabricated with notches (cracklike reflectors) and indentations to test the longitudinal and shear wave techniques. Ultrasonic signals from the reflectors in the reference pin and the pin on the bridge were digitized and processed in a computer. The acoustic signals were extracted from the record and a Fourier transform was performed to display the frequency spectrum. A portable, computer based ultrasonic data acquisition system was fielded on the bridge to acquire the ultrasonic data. This data was processed in the laboratory for comparison with the reference data taken on a calibration specimen, Figure 2 shows the comparison. 
The ultrasonic signals from the bridge and the signals from the reference reflector were not similar. It was speculated then that the pin might be fused to the eye bars and thus the acoustic signal could be couple from the pin into the plates. Figure 3 is a schematic which diagrams this situation. If this coupling of ultrasonic energy was occurring, the reflected ultrasonic signals could appear to be cracks in the pin. On the bridge, ultrasonic energy generated at the pin was received on the surface of the eye bar. For the ultrasonic energy to pass from the pin to the eye bar, the interface needs to be fused.

High Energy Digital Radiography

Practical and cost effective digitization of radiographs is now possible using commercially available equipment. Digitization of radiographic images allows the computer enhancement and quantitative analysis of the images to improve sensitivity and probability of detection. Signal processing software can minimize system and random noise, improve edge sharpness using point spread function deconvolution of system unsharpness, filter out scatter related noise using models, and color code the images. These techniques provide improved defect detection and damage assessment. Our signal processing is performed using an LLNL code called VIEW which readily handles image data in an open ended environment. This permits selection of appropriate application specific techniques. The VIEW code contains over 300 commands and handles 1, 2, 3, or 4 dimensional data in bit, byte, word, real and/or complex format. We demonstrated our image enhancement capabilities on two bridge components, rebar imbedded in concrete and steel cables enclosed in an end cap. Figure 4 displays a digitized image of several different sizes of rebar buried inside a one foot cube of concrete. The rebar had a variety of notches cut into it to simulate defects. Figure 5 is a digitized radiograph of a cable end socket. The enhanced image of the steel cable clearly displays corrosion damage and broken strands.

Computed Tomography 
Computed tomography (CT) is an established technique for in-plant inspections, however, there has not been significant field application of CT on large structures. Large structures in the field are not always accessible from all sides to allow acquisition of full 360 degree CT data sets. To solve this problem, we have developed the reconstruction algorithms and signal processing needed to produce CT images from limited data sets obtained from both film and real-time radiography systems. The films were placed directly behind the cable resulting in a effective beam width for imaging of approximately 0.1 millimeters. This source-to-film geometry (a half-fan angle of 1 degree) justified the use of parallel-beam reconstruction techniques. We employed an in-house developed Filtered-Back-Projection routine on all the 2D slices. A rotational center was calculated from each sinogram using a routine developed by LLNL. Three-dimensional views of the cable were built up by stacking the 2D slices together. The images were digitized with a 210 micrometer pixel size, and reconstructed into voxels of the same size. The reconstructed images were nominally 320 by 320 in total size, and this could be adjusted by re-digitizing at a smaller pixel size or by reconstructing to a different voxel size. It is anticipated that the limitations on the spatial resolution will derive from the small number of views and nrt characteristics of the radiographic technique.

The limited view CT technology was applied to a bridge cable and end cap which had been removed from a bridge. A portable linear accelerator was the radiation source and film packets detected the $x$-ray energy. The experiment produced 2-dimensional images at 23 views over 138 degrees around the cable end cap. The 23 films were digitized and all views were normalized to the same attenuation mass. CT reconstructions were performed on the digitized data sets. Figure 6 is the CT reconstruction of the end cap. Locations and amounts of cable separation and loss of mass were determined.

\section{Dual Band Infrared Imaging}

Our Dual Band Infrared (DBIR) thermal imaging technique was developed for remote imaging of hidden structural defects by mapping precise surface temperature-difference patterns in steps of 0.2 degrees Celsius. The DBIR 
technique simultaneously records two passive IR bands and decouples temperature from surface emissivity noise (eg. roadway roughness variations, oil stains, paint, grease, markers, trash). A mathematical approximation derived from Planck's Radiation Law allows the DBIR technology to provide both surface temperature and surface emissivity-ratio images to reduce false detections by locating and removing clutter. We are applying this dual band infrared imaging on concrete slabs with embedded defects. Our intention is to develop an infrared imaging method to detect delamination sites in concrete bridge decks.

A power law model [1] explains how infrared signals vary as a function of the surface emissivity and the surface's absolute temperature:

$$
I \lambda \sim \mathbf{e}_{\lambda} \mathrm{T}^{50 / \lambda}
$$

where $\mathbf{l} \lambda$ is the intensity at a given wavelength, $\mathbf{e} \lambda$ is emissivity at that wavelength, $\mathbf{T}$ is in temperature in Kelvin and $\lambda$ is the wavelength in micrometers.

We can obtain temperature alone by computing the ratio

$$
R=\frac{I_{5}}{I_{10}}=\frac{e_{5} T^{50 / 5}}{e_{10} T^{50 / 10}}=\frac{e_{5}}{e_{10}} T^{5}
$$

For a greybody, e5 $=\mathbf{e} 10$ and $R \sim T^{5}$.

We can obtain the emissivity ratio by computing

$$
\frac{\left(I_{10}\right)^{2}}{I_{5}}=\frac{\left(e_{10}\right)^{2\left(T^{5}\right) 2}}{e_{5} T^{10}}=\frac{\left(e_{10}\right)^{2}}{e_{5}}
$$

This ratio is sensitive mostly to surface objects which have very different emissivities at 5 and 10 micrometers. 
We then compute the normalized ratios to obtain temperature and emissivityratio (E-ratio) maps:

$$
T=\ln \frac{S / S_{\mathrm{av}}}{L / L_{\mathrm{av}}} \text { and E-ratio }=\ln \frac{\left(L / L_{\mathrm{av}}\right)^{2}}{S / S_{\mathrm{av}}}
$$

where $S$ is the short-wavelength intensity (e.g., $I_{5}$ ), Sav is the average value of the pixels in $S, L$ is the long wavelength intensity (e.g., $\left.I_{10}\right)$ and $L_{a v}$ is the average value of the pixels in $L$.

Several other corrections are also applied to the DBIR scanner signals as needed (e.g., for absorption and reemission in the air path between the scanner and the surface, and for reflected infrared (IR) radiation. $[2,3,4]$

\section{Summary}

The aging infrastructure of this country is a monumental problem. One aspect of the situation is the grave condition of our bridges. Nondestructive evaluation is a way to assess the severity of the bridge damage and help plan an economical repair program. Transferring advanced nondestructive evaluation technology to field applications will improve bridge inspection capabilities. A fieldable version of these technologies will have to be developed before it will be applicable to the hostile bridge environment.

\section{Acknowledgments}

Work performed under the auspices of the U.S. Department of Energy by the Lawrence Livermore National Laboratory under Contract W-7405-Eng-48.

\section{References}

[1] N. K. Del Grande, G. A. Clark, P. F. Durbin, D. J. Fields, J. E. Hernandez and R. J. Sherwood, "Buried Object Remote Detection Technology for Law 
Enforcement" in SPIE Vol. 1479 Surveillance Technologies, pp. 335-351, April 1991.

[2] N. Del Gi ande, "Sensor Fusion Methodology for Remote Detection of Buried Land Mines" in Proceedings of the 3rd National Symposium on Sensor Fusion, Vol. 1, pp. 407-427, ERIM, Aug. 1990.

[3] N. Del Grande, "Temperature Evaluated Mine Position Survey (TEMPS) Application of Dual-Band Infrared Methodology Proceedings of the 1990 Meeting of the IRIS Specialty Group on Passive Sensors, IRIA/ERIM-sponsored, Baltimore MD, March 1990.

[4] L. A. LeSchack and N. K. Del Grande "A Dual-Wavelength Thermal Infrared Scanner as a Potential Airborne Geophysical Exploration Tool", in Geophysics 41, p. $1318,1976$. 


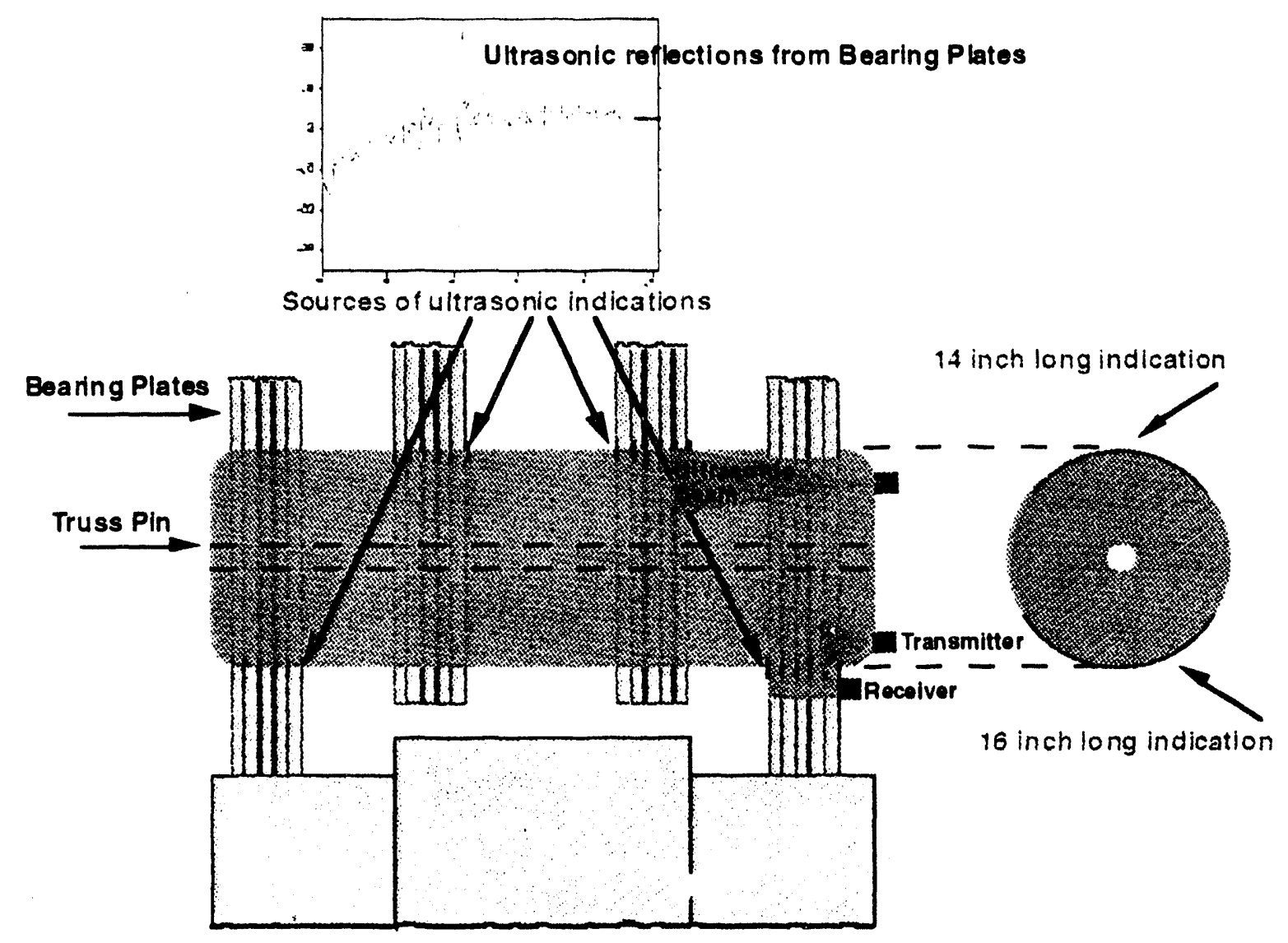

Figure 1 - Diagram of ultrasonic inspection of San Francisco Bay Bridge Pin which supports Pier E-9. Note the ultrasonic reflections. 

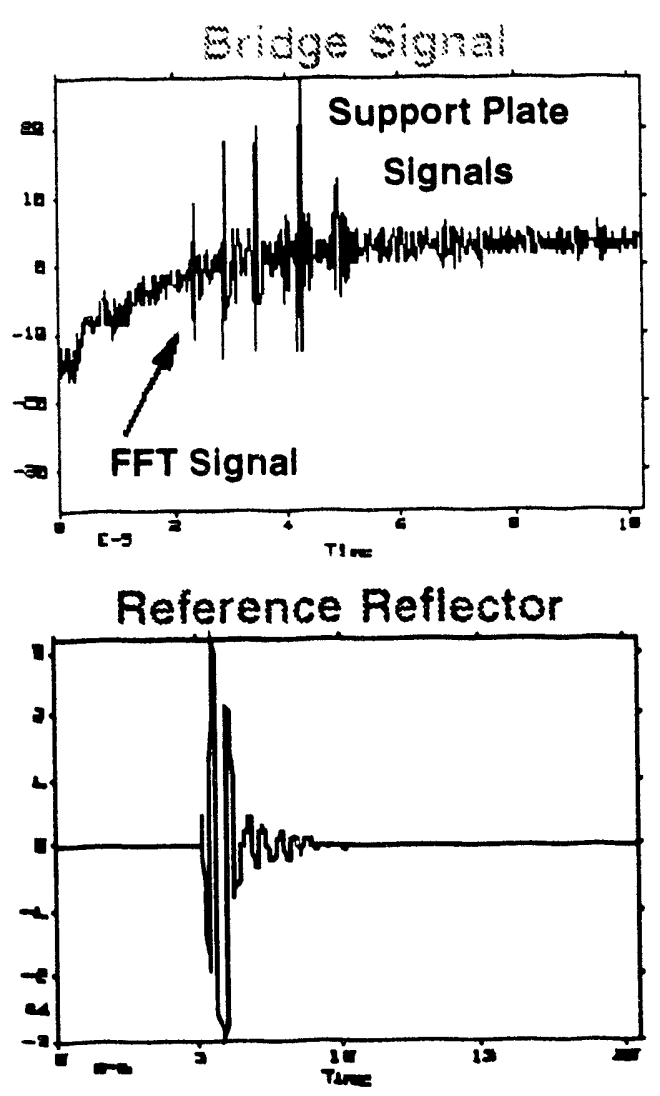

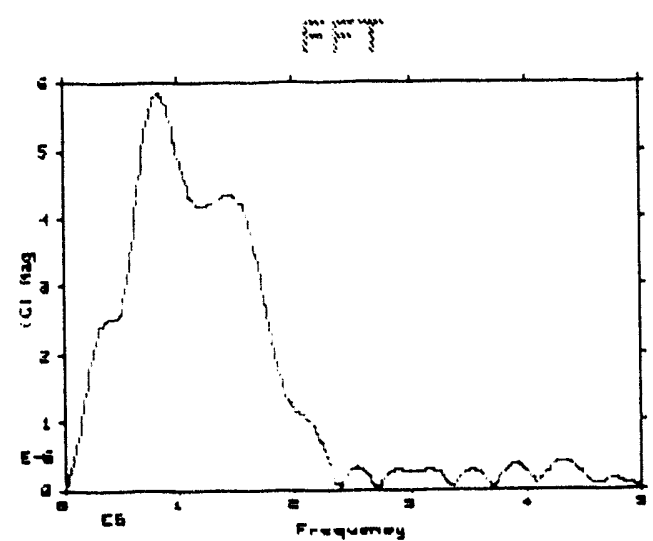

FFT

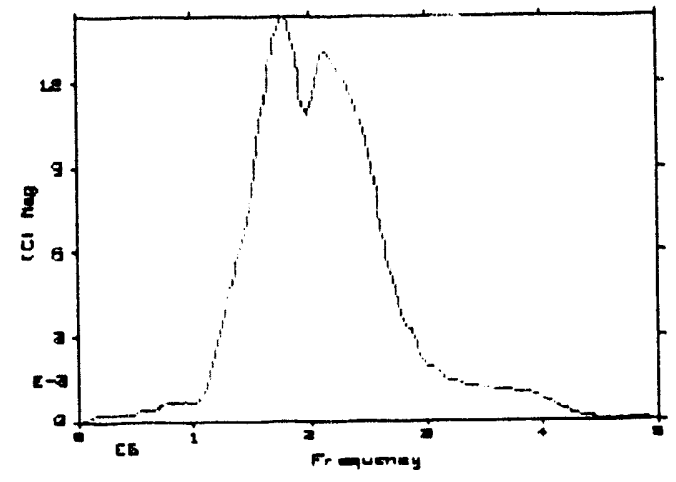

Figure 2 - Comparison of ultrasonic data between signals from bridge and signals from crack like reflector in laboratory reference. Signals do not appear to correspond. 


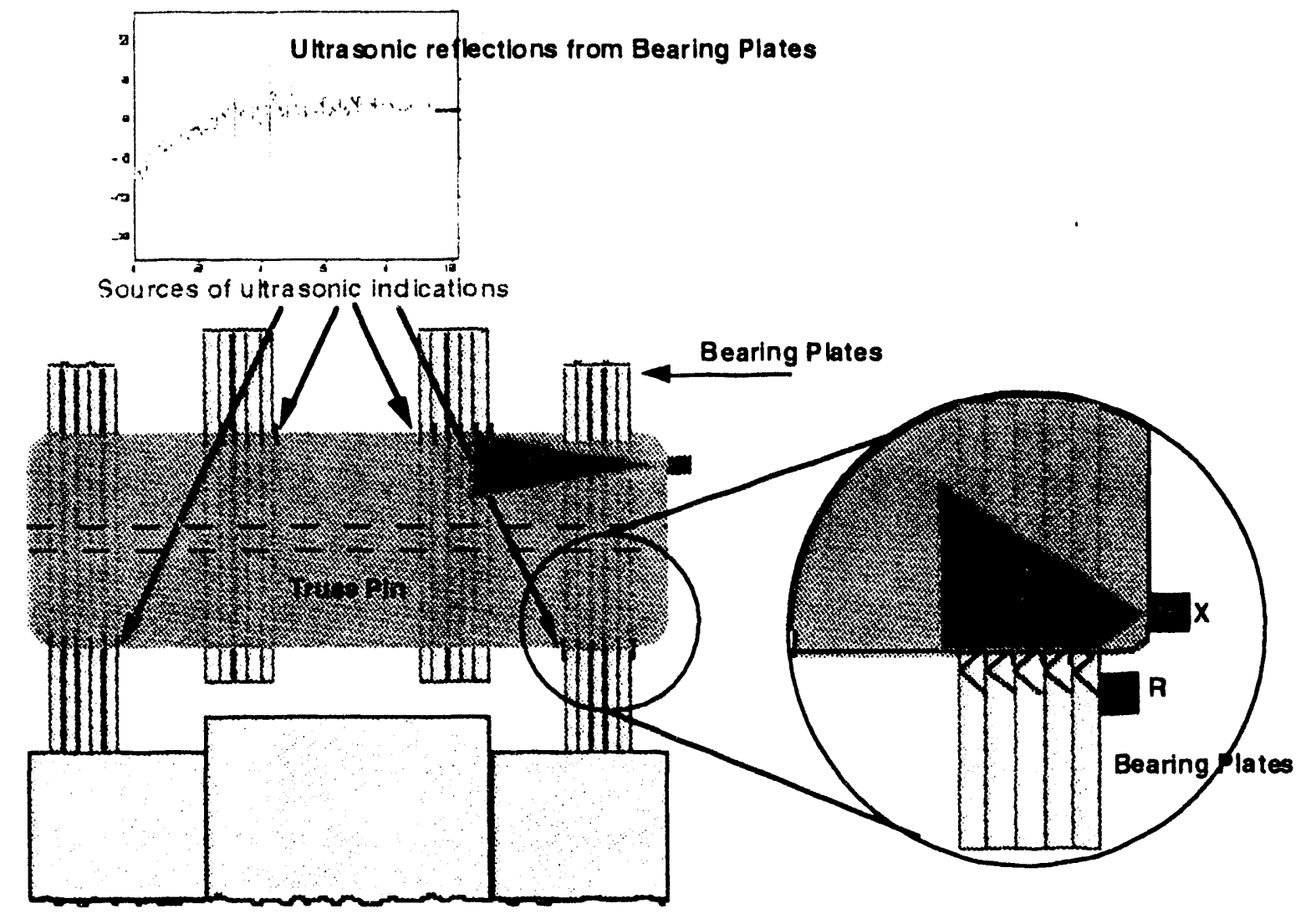

Figure 3 - Diagram of experiment to demonstrate the coupling of ultrasonic energy through the pin to bearing plate interface. 
30 (n)

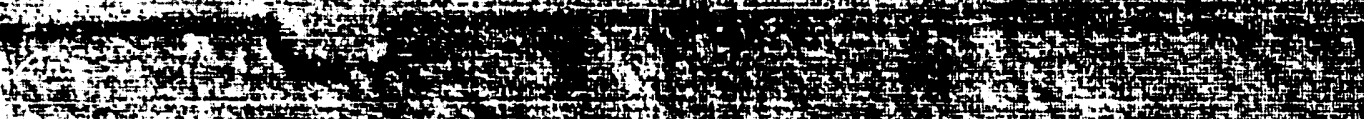

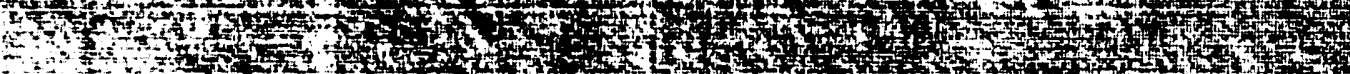

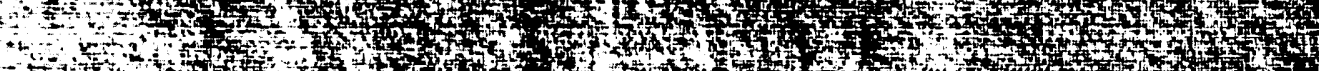
a. -30

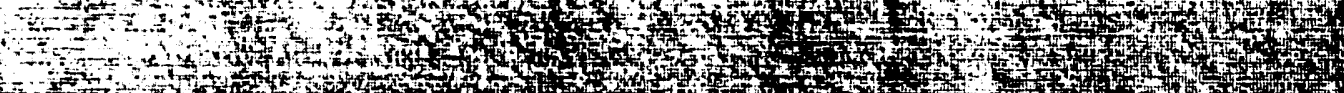

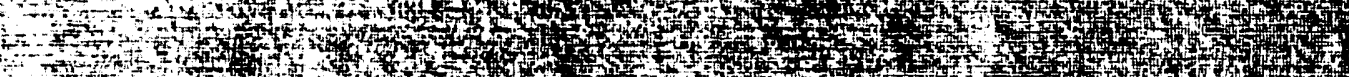

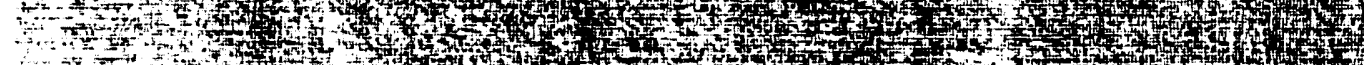
a

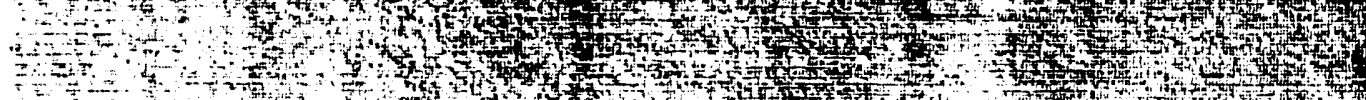
r.

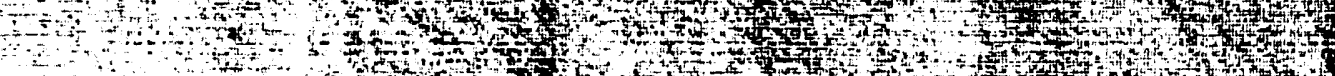

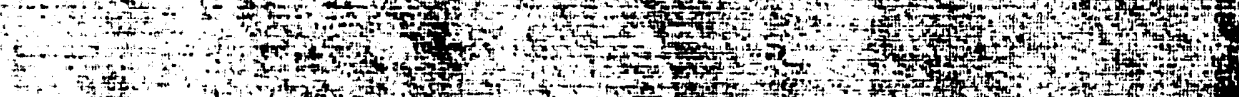

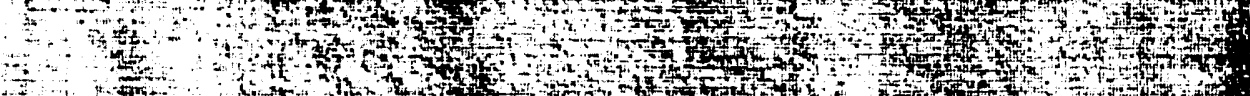

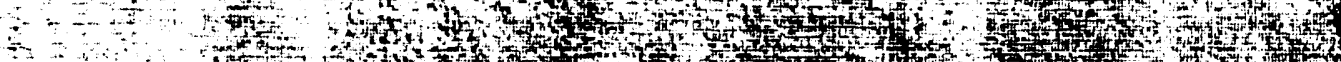

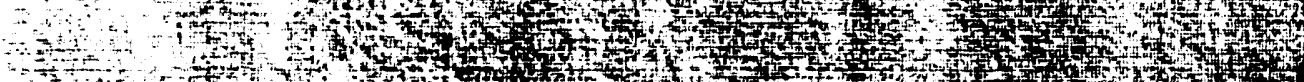

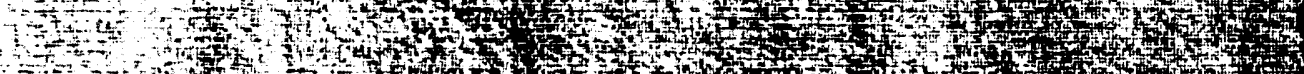

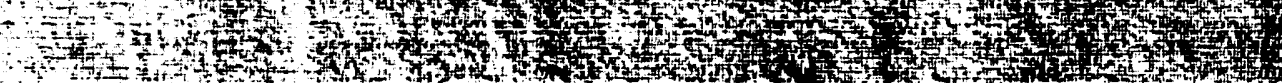

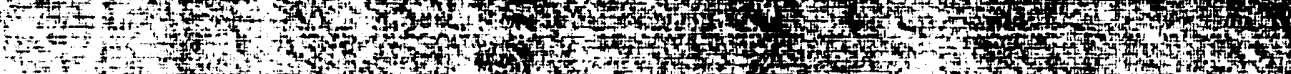

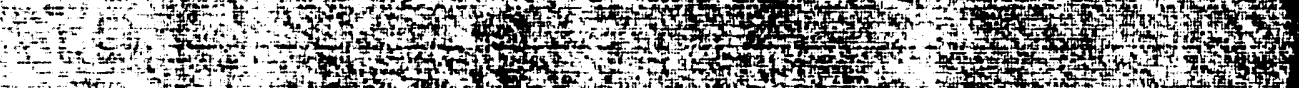

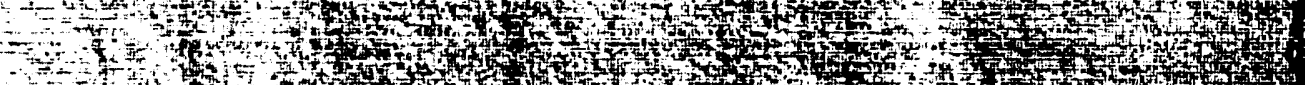

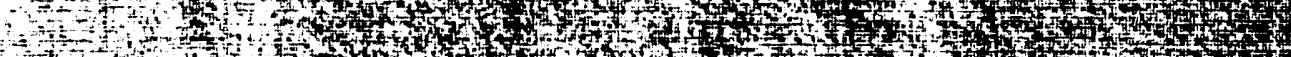

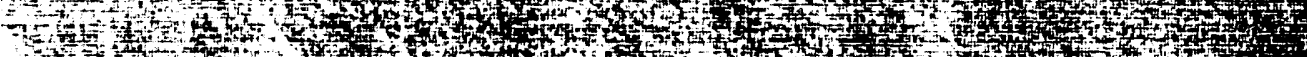

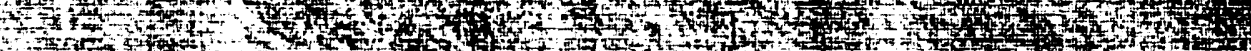

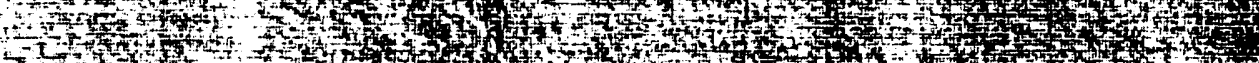
$2-1$
$n$

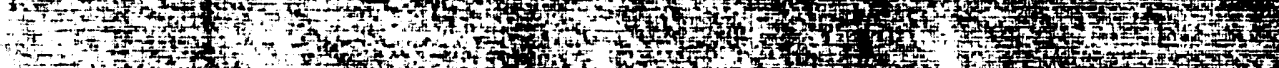

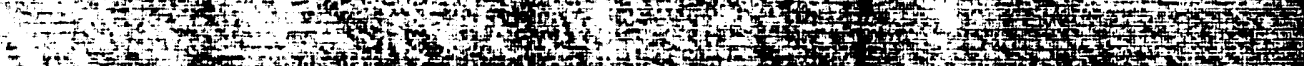

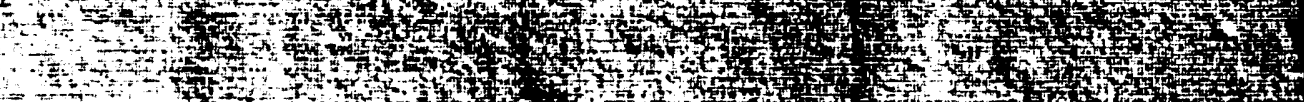

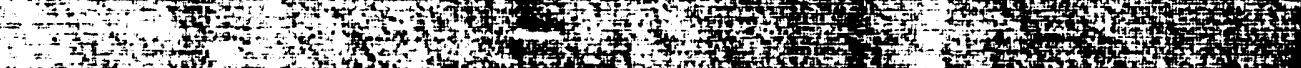

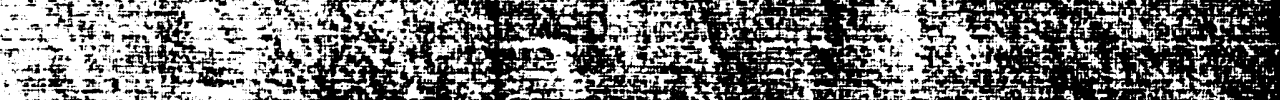

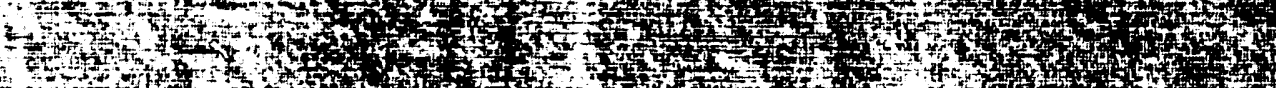

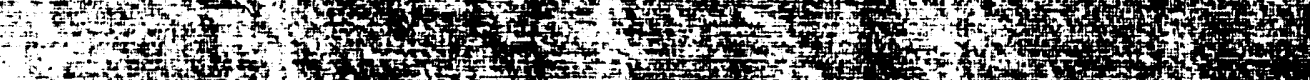

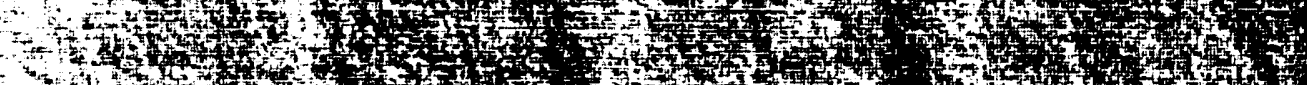

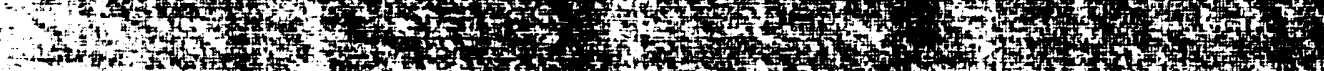

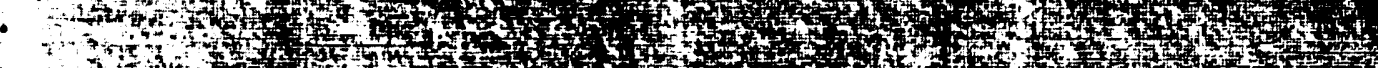

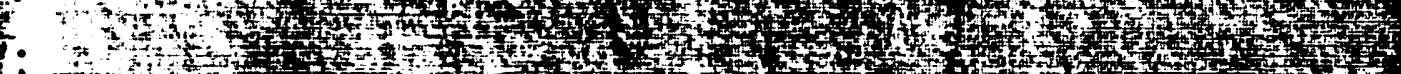

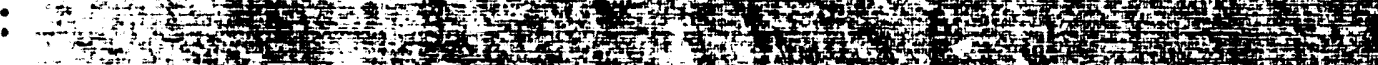

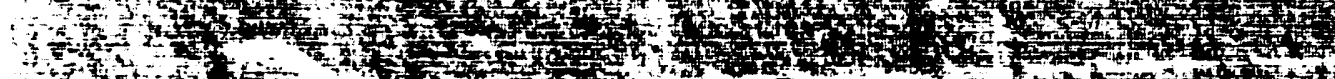

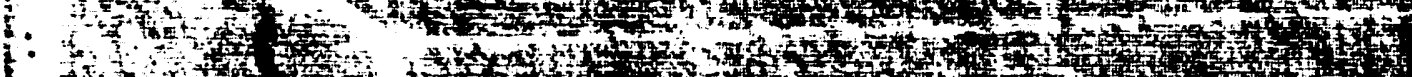

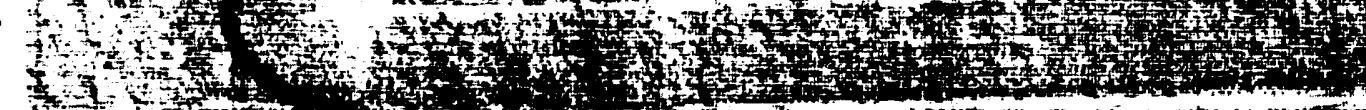

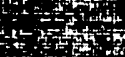
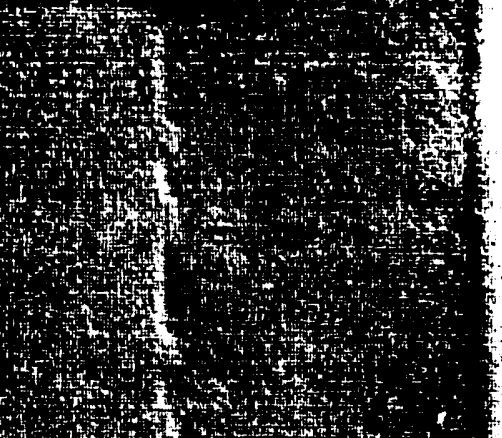

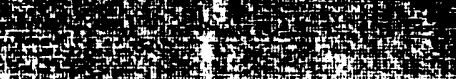

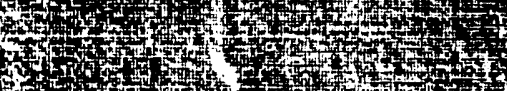

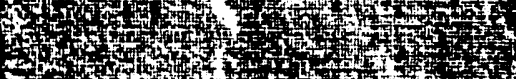

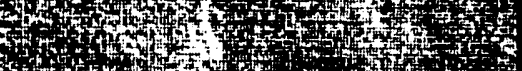

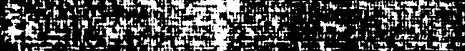

\author{
the
}
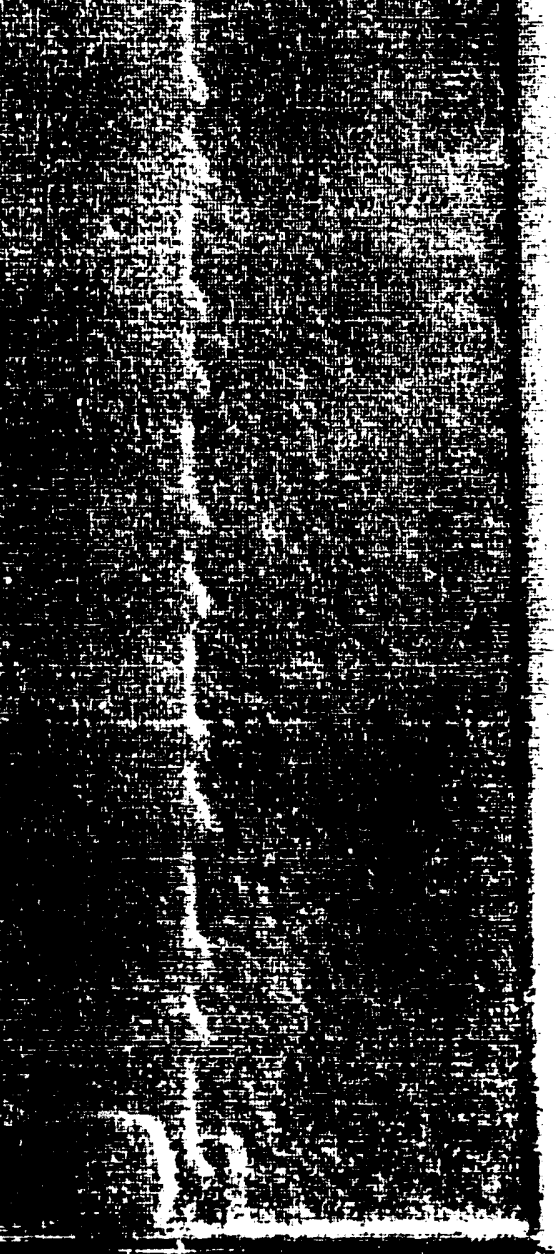

Figure 4 - High energy $x$-ray of rebar in a one foot cube of concrete. Note resolution of notches sawn in rebar. 


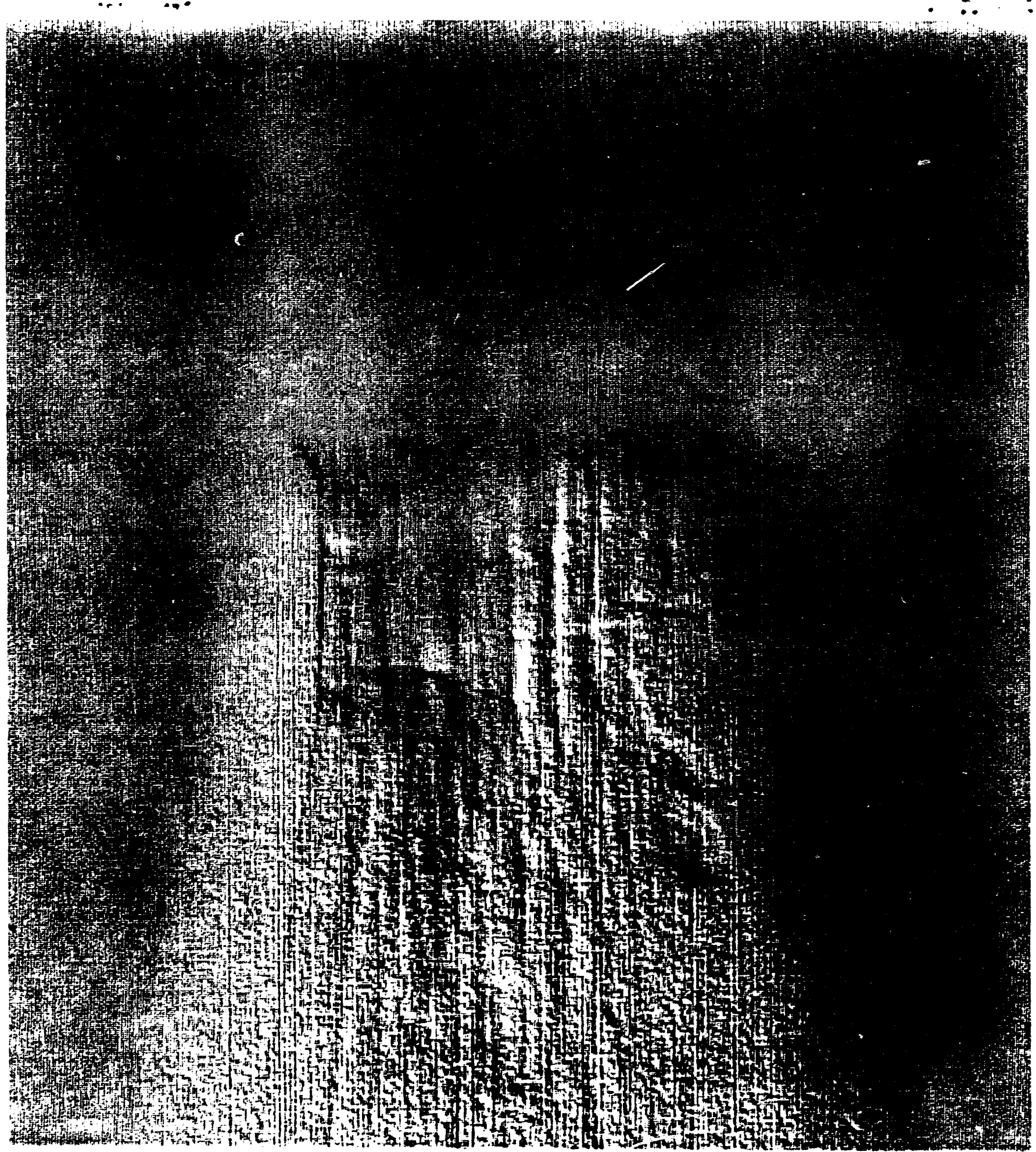

$\frac{0}{2} \frac{0}{2} \frac{0}{8}$

乙

这 $\frac{\Phi}{\omega}$

ชิ .

동 음

Ф

至

등

옴

은 옹

$\leftarrow$ 등

등

त

ํํㅇ

ํํㄴ

회 은

잉

ธ

등 흥

을 읃

으음

$\stackrel{\mathbb{N}}{\stackrel{2}{\Xi}}$

흠옹

产 


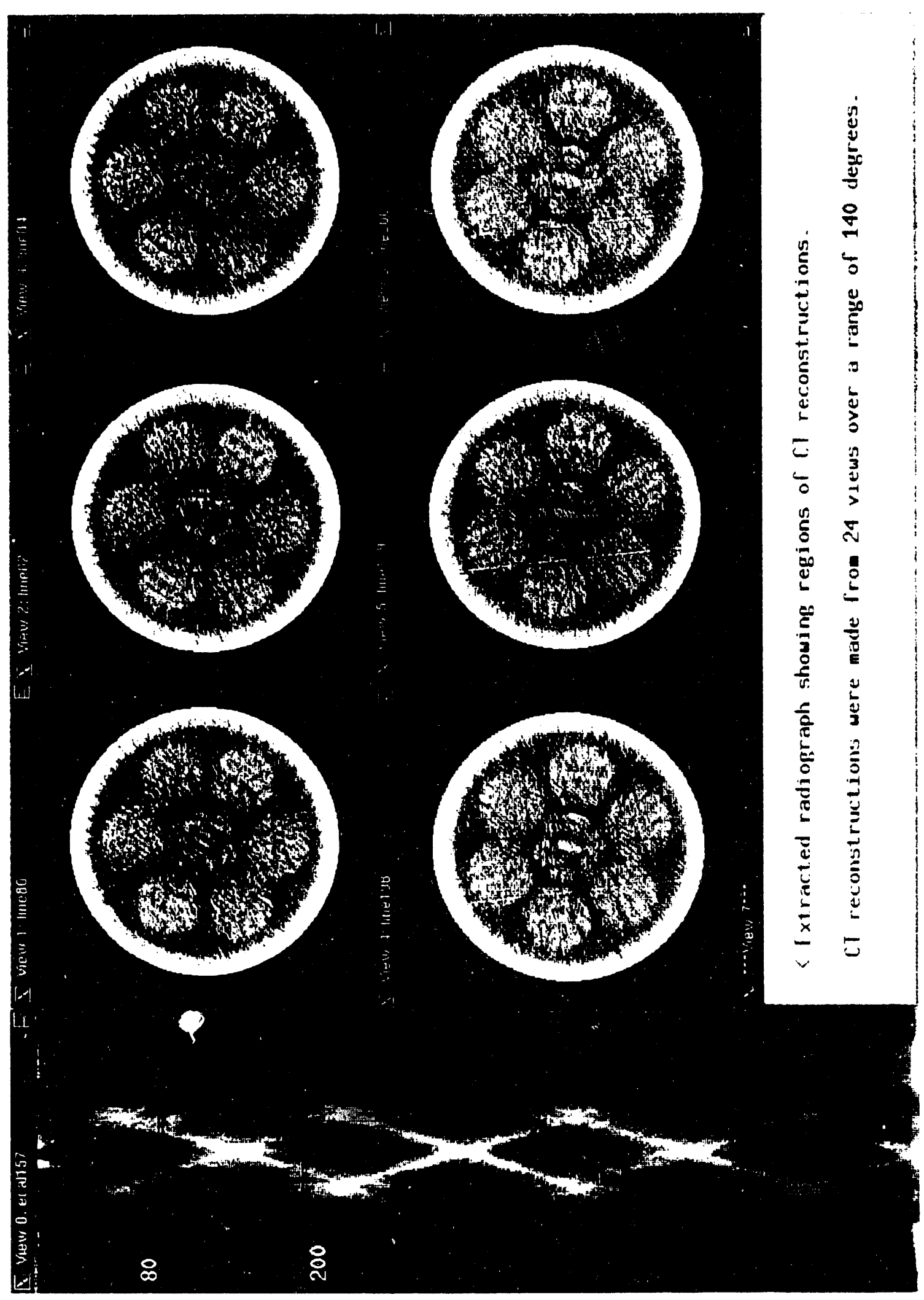

Figure 6 - Computer tomographic slices of bridge cable. Individual steel strands are visible. 

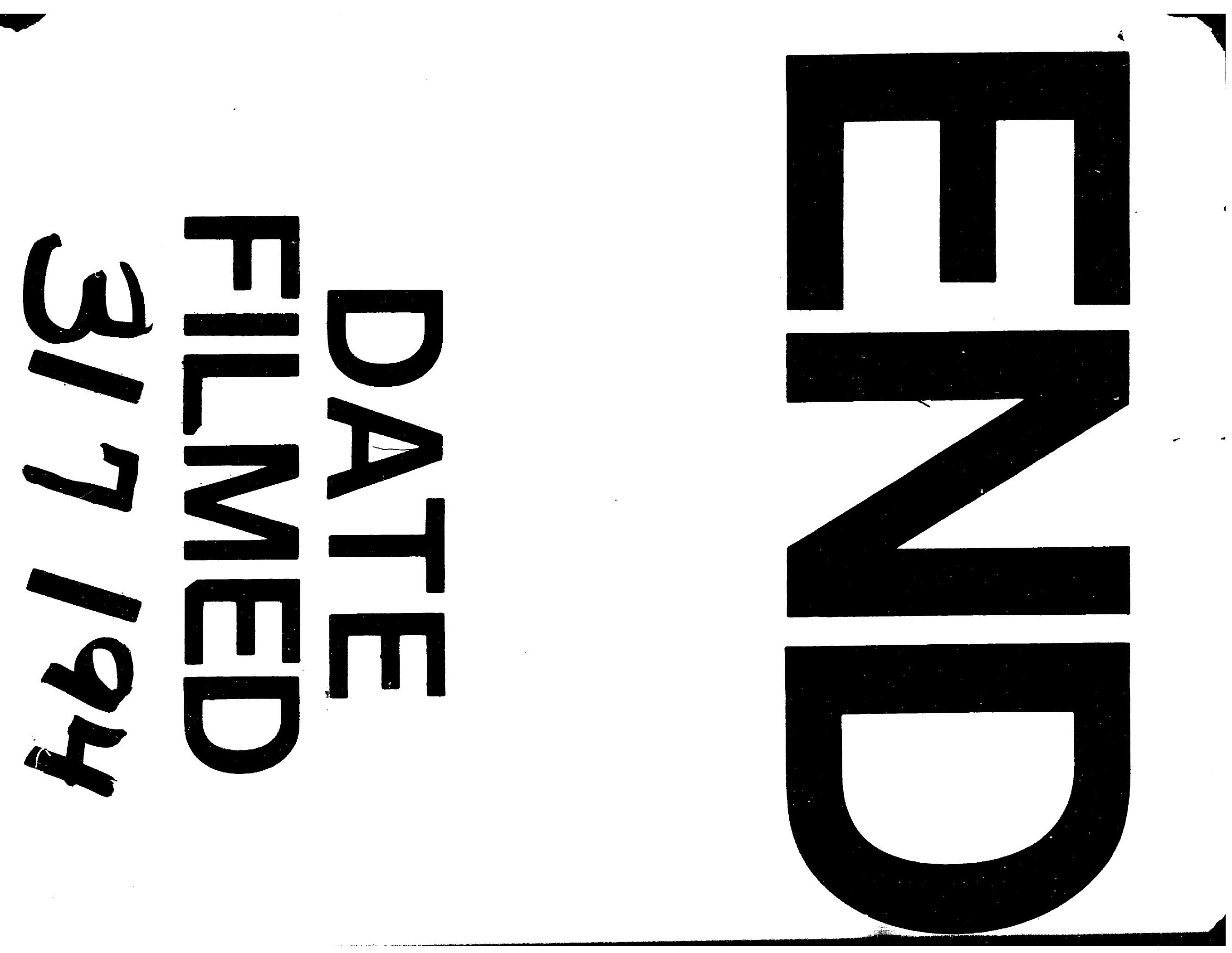
